\title{
A STUDY OF AMBIENT NOISE IMPROVE OF COMMUNITIES ELEMENTARY SCHOOL: NOISE MAPPING APPROACH
}

\author{
Kuo-Chung Wen \\ Associate Professor \\ Graduate Institute of Architecture and Urban \\ Planning, Chinese Culture University \\ 55, Hwa Kang Road, Yangmingshan, Taipei 111, \\ Taiwan, R.O.C. \\ wenkc@ms1.hinet.net
}

\author{
Yung-Hsin Chang \\ Postgraduate Student \\ Graduate Institute of Architecture and Urban \\ Planning, Chinese Culture University \\ 55, Hwa Kang Road, Yangmingshan, Taipei 111, \\ Taiwan, R.O.C. \\ celesforyou@yahoo.com.tw
}

\begin{abstract}
In recent years of Taiwan, the city turns a phenomenon development quickly, causing the city population increase suddenly. The usage of various vehicle and machine equipment increases increasingly, making the situation quality of the city noise pollution turn worse increasingly. Be located the campus in the city and it closes to community of the quality of life also is subjected to tremendous influence.

This research uses environment noise inside the community elementary school and its school district as to investigate object. Inquire into its environment noise to distribute situation according to the time space idea. This research also makes use the noise map of the community elementary school by spatial information technology and its school district to provide the basis with this research reference.

This research anticipates to take elementary school as center, school district for investigate scope. With the environment noise of digital sound survey meter each street corner inside the school district, and photograph the situation of the noise source and residents' activity to assistance analysis, the basis been an environment noise factor to induce in this research.

Expect a result: Inquire into the situation that the environment noise of the elementary school distributes, and to draw up the improvement strategy of the environment noise for community elementary school.
\end{abstract}

\section{KEYWORDS}

Ambient Noise, Communities Elementary School, Spatial Information Technology 


\section{INTRODUCTION}

Taiwan is crowded and makes our living space coexistence with many different noise factors. The revelation in long time is under the noise environment, not only may make quality of life low to fall, daily life work and rest also will the noise is the interference [1].

And the community is the main region of people's daily life; the school is the citizen's enlightening of education and knowledge point. Among them, the elementary school is the highest learning unit in a popularization rate, is also education center of gravity place in the community $[2,3]$.

This text tries Noise Mapping to construct the noise in Taipei metropolis to distribute situation. Object then in order to take primary school campus as the volume of the community environment of center, and adoption GIS imitate inside the community and the noise inside the campus distribute situation. Match with noise to defend the area of the noise control that system method delimits, examine noise to distribute situation whether have already matched standard inside the control area, and inquire into the improvement method of decrease noise [4]. Therefore the origin studies a purpose as follows:

1. The community primary school its environment noise distributes what is situation?

2. What is the improvement strategy of the community primary school environment noise?

\section{RESEARCH}

\subsection{Ambient Noise}

One of the topics of this research is an environment noise. This stanza will make the comprehension of one first step to the definition of the generous character, environment noise of voice and to influence and laws level of human body. Then can carry on a follow-up inquisition research [5].

\subsection{The Calculation of Voice}

The scope of the sense with hearing frequency, is ordinary people's ear, between $20 \sim 20000 \mathrm{~Hz}$. The orotund pressure that the minimum audibility goes to is $20 \mu$ Pas. The measurement of voice usually takes orotund power, orotund strength, orotund pressure as generous character object, and according to person the ear becomes to the scope conversion that the frequency can feel quasi. Generally speaking, when the orotund pressure quasi- variety measures to 3 decibels, person ear the square can start checking to feel. When the variety measures to 5 decibels, person's ear can know to check and feel. And while changing to change into 10 decibels, person ear to it rings the feeling of degree about is original of 2 times. Voice is by object vibration cause, vibrates a creation pressure perturbation, and in common use pressure unit is Pascal [6].

\section{THE INFLUENCE OF THE NOISE UPON THE HUMAN BODY}

Environment's influence of the noise upon the human body is extensively very huge, and influences people's various activity [7] [8]. As hinder confabulation, influence sleep and take a rest, interference work, make the power been subjected to damage and even cause various disease etc.[9].

\subsection{Geography Information System}

Geography information system isn't an independent research realm, is the common ground of that information processing and other exploitations go to space to analyze each different realm of technique. It combined a computer to draw to measure, the Yao probe into, data management and $\mathrm{CAD}$ four technique essences of realms and become. The basic geography information system should can integrate processing, analysis and search function of sketch data and attribute data.

\subsection{Noise Mapping}

Noise Mapping is a kind of technique that is on the map the performance of the noise effect and 
includes Noise Contour explicit map. Put together related geography information and noise degree knot with the accurate method. Noise Mapping can used to the tool of programming and the monitor of the environment noise and its purpose does a valid decrease and control to the whole amount of noise (Figure 1).

The Commission of European, the EC announces Green in 1996 Paper Policy of Noise of on Future, put forth the standpoint of "decrease living whole noises, is neater in importance than settling the place position of other environment subjects", make the public understood and discuss the direction of the noise policy in future. The purpose of Noise Mapping is being on the map the influence performance of noise [10].

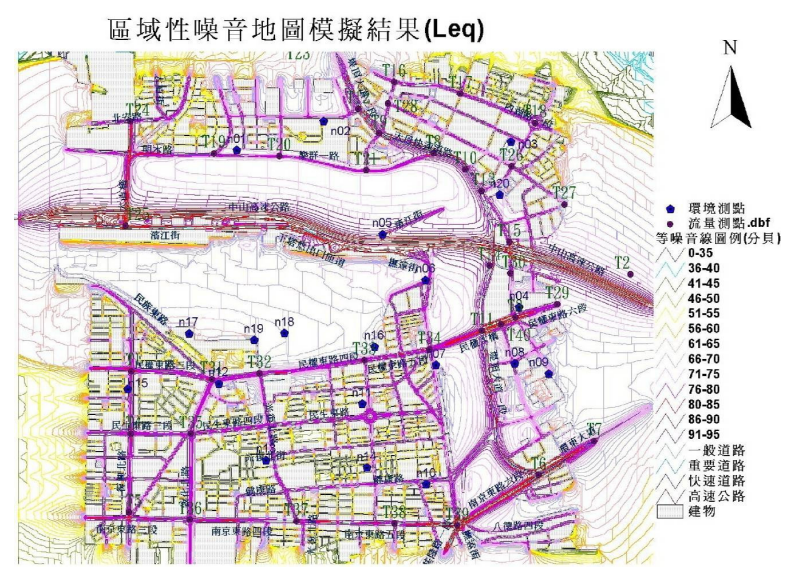

Figure 1. The local area noise map imitates result diagram. (Environmental Protection Administration, 2007)The different noise is with the different color compartment. In regard to this map, the main trunk highway traffic noise is about 71-85 decibels and indicates by the purple color and the red. Road building area the volume is about $46-60$ decibels and indicates by the yellow and the green. Generally speaking, the volume is higher and the color is deeper.

The Environmental Protection Administration introduces experience that the EU national city noise map designs in the Year 96's.Evaluate the feasibility and benefit that the native local area city noise map designs. The first step delimitation scope covers the mountain in Taipei City,
Sunshine and inside three administrative areas in the lake; the area is about 25 square kilometers. The volume distributes a result to contribute to an estimate and evaluates the influence of foreign noise source and has great help to the noise control and the improvement [11].

\subsection{OPERATE PROCESS}

This research takes geography information system, noise map, space information system...etc. as foundation to carry on the construction of theories. Analyze the campus of the theories construction and community information by GIS space, and consider noise inside the community to distribute situation in the construction process of noise map. Make use of the community of the system construction of the space information and the noise map of campus according to time and the idea of space. The basis made reference to while providing this research to imitate.

\subsection{The Problem Analyzes a Definition}

The certain research topic is constructing the integration that the noise distributes situation and geography information and design by noise map of way to reach. The research object takes community primary school in the text mountain area as center and inquires into that the noise of campus and neighboring community distributes situation and correlation in the meantime. The method that the noise map designs, by sound source really certainly, environment of enactment, spread the calculation of path etc. Consequently there is necessity carrying on understanding to the theories structure of noise related problem before carrying on a research.

\subsection{The Characteristic of the Noise Mapping}

Because when the noise map designs, the variable considered is rather many. Related and conditional change all will for cause the influence of different degree as a result. For completely imitating according to the actual situation, hope to have regard for variables, such as all relevant sound sources, dissemination path and environment condition... etc. 


\section{WITH DYNAMIC STATE TIME THE IDEA CONSTRUCT OF THE COMMUNITY NOISE MAPPING}

In the data of the measurement noise, not only adopt fixed-point measurement in fixed time, also will consider neighboring community and the daily schedule of the campus school-children. Up increase the concept in time at the noise mapping. Design the noise map of various different times to inquire into that the different daily timetable noise distributes situation.

\subsection{Operates}

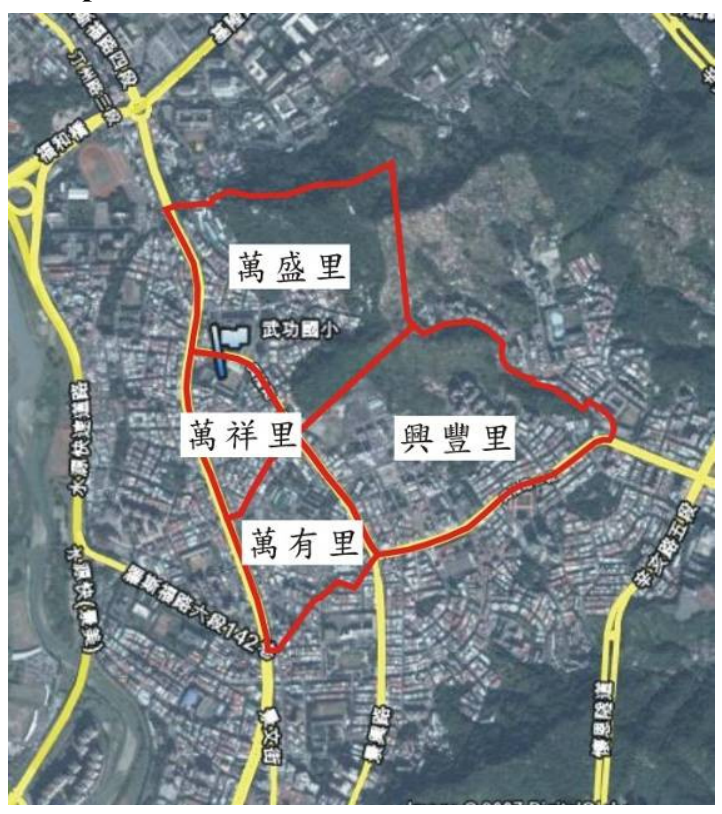

Figure 2. School district in the W-Kung elementary school

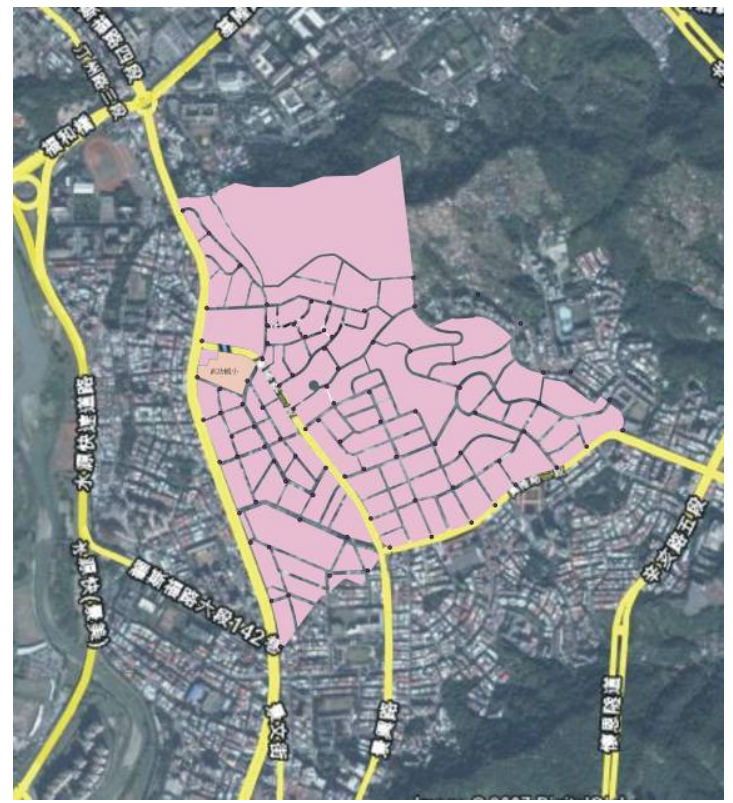

Figure 3. Investigate the scope

\subsection{The Street Noise Measurement Plans}

Handing over to order by the measurement road inside the scope is a measurement to order and add up to 89 to measure a point. Measure time as Monday to five every mornings Am 8:00 to Pm 20:00, add up to for 12 hours. Measure a way in order to leave ground 1.2 meters, the frequency sets for $\mathrm{DbA}$ LO(Low)- Weighting: 35- The HI(High) of $100 \mathrm{~dB}$ and DbA- Weighting: The $65-130 \mathrm{~dB}$ is 2 kinds. Each on measuring some measurement times as 5, take biggest of the value is a record, and at each time on measuring some measurement three times, the partition is 10 each time, measurement completion then go to next measure a point, each measure some partition times as 2 minutes (2004) . 

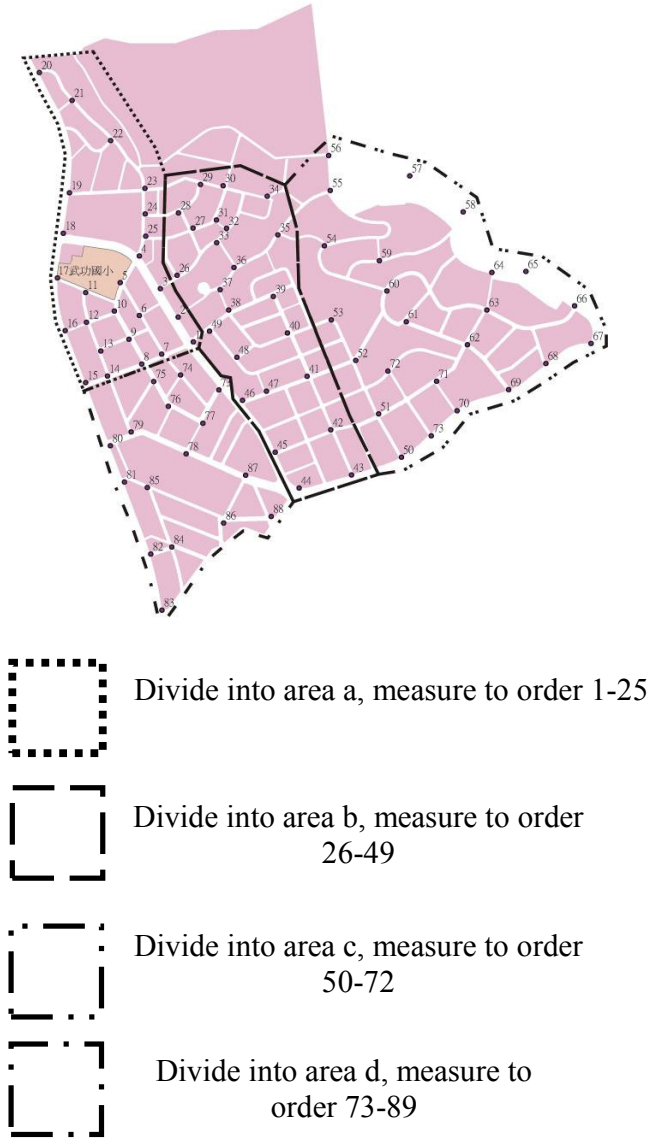

Figure 4. The map

\section{MEASUREMENT RESULT}

Relate to the variety of the measurement data by the inverse distance weighted (IDW) tool, do an estimate in the bad method. Measure the data of some inside the measurement scope by estimating with this, and express according to the color depth. This research with Model Builder IDW the tool construct for Model, make use of the work of its automatism assistance IDW (see Figures 5-17).

Be canned know as a result by the measurement, the noise quantity of the Hsin-Lung road and Roosevelt's street corner is the highest, is also influence this noise of the diagraph scope quantity of measure a point.

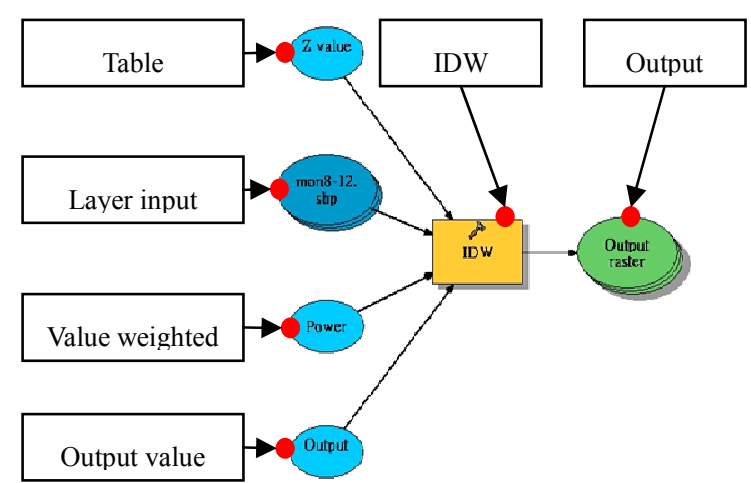

Figure 5. IDW Model

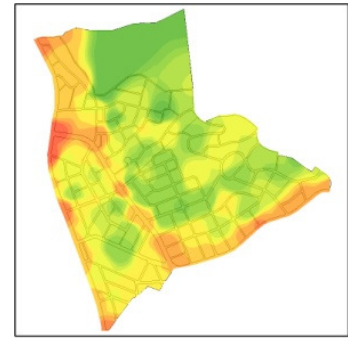

Figure 6. Mon 8-9

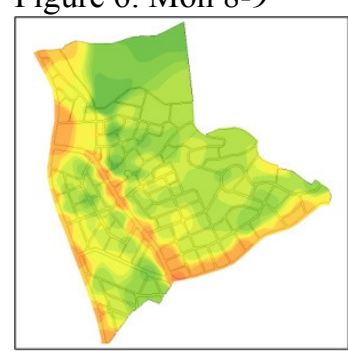

Figure 8. Mon 12-13

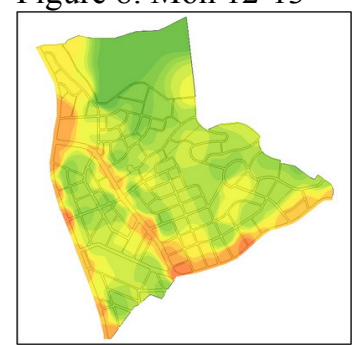

Figure 10. Mon 16-17

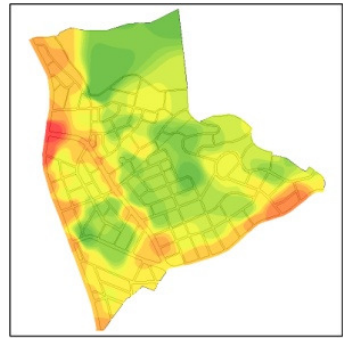

Figure 7. Mon 9-10

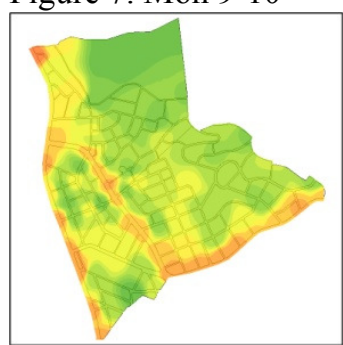

Figure 9. Mon 13-14

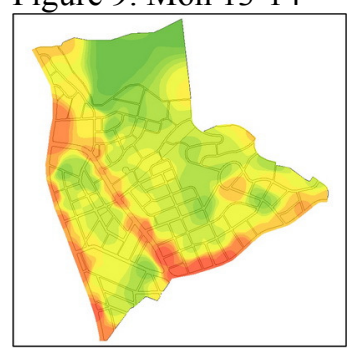

Figure 11. Mon 17-18 


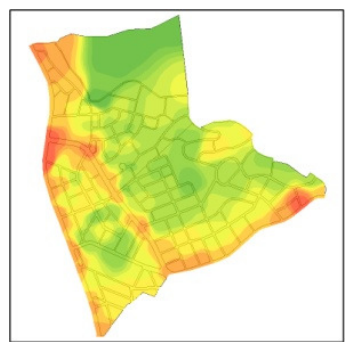

Figure 12. Mon 10-11

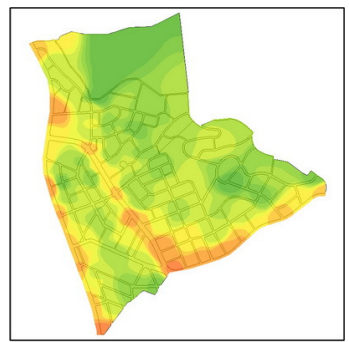

Figure 14. Mon 14-15

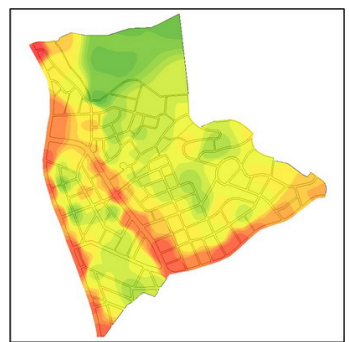

Figure 16. Mon 18-19

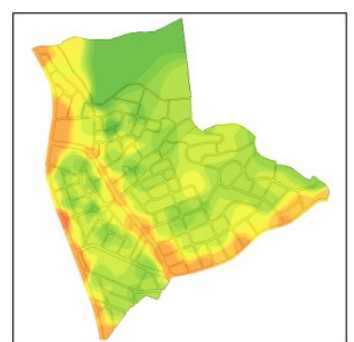

Figure 13. Mon 11-12

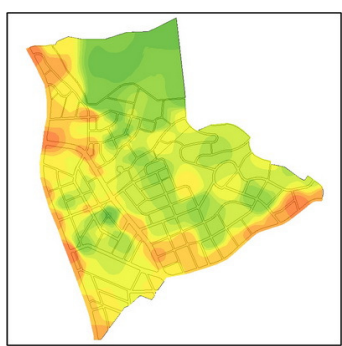

Figure 15. Mon 15-16

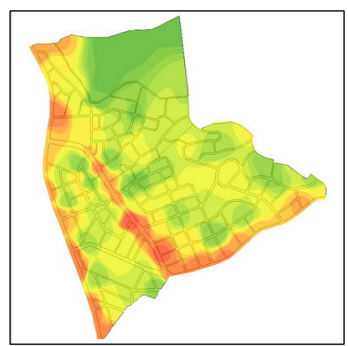

Figure 17. Mon 19-20
$\mathrm{Db}$

40-50

50-55

55-60

60-65

$65-70$

70-75

75-80

80-85

85-90

90-95

95-100

$100-120$

\subsection{The Laws Checks Against}

For understanding noise serious degree, this research makes measurement result and laws a check against. Because this measurement regards traffic noise as principle, consequently check against Category 2 of the environment volume standard Article 4 and Category 3 of the method of the noise control, the daytime traffic noise quantity basis is worth $74 \mathrm{Db}$ to be used as basis. Exceed noise to distribute a region to mark (see Figures 18-29).

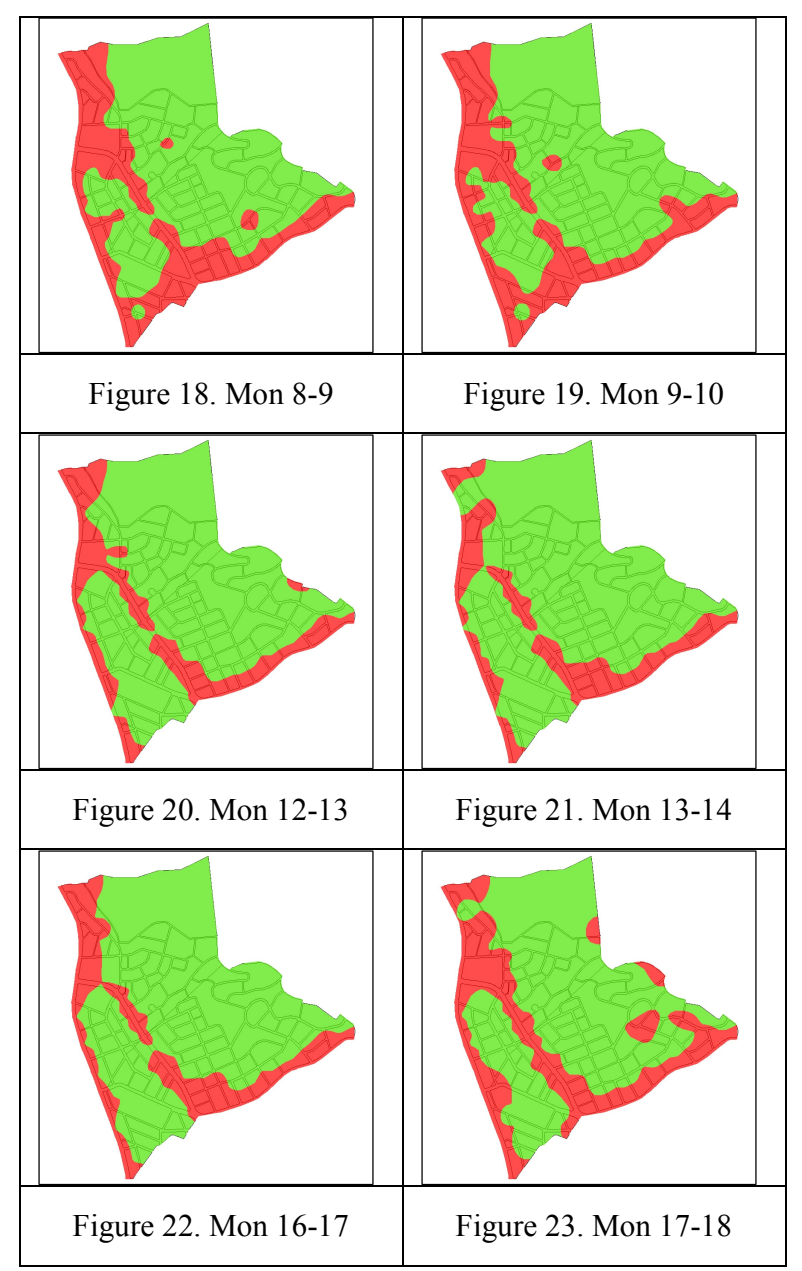




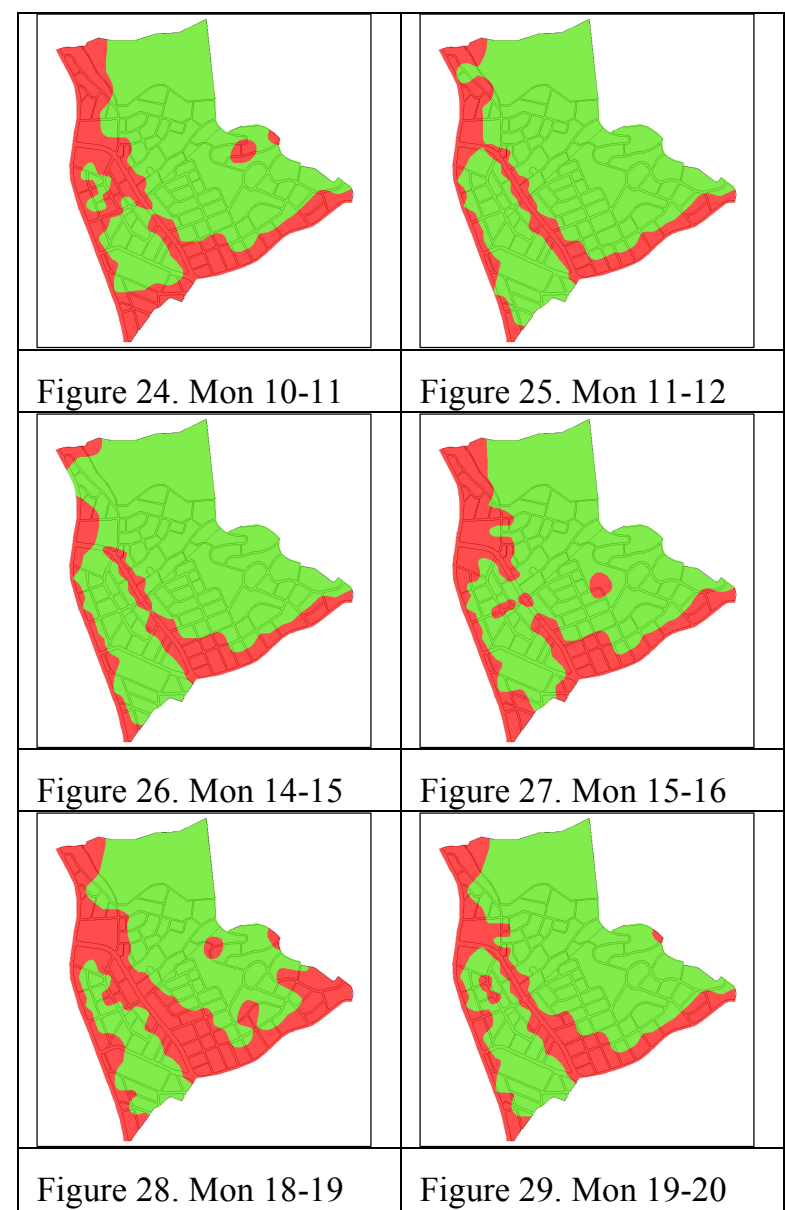

Among them, green district's representing this measurement result is lower than traffic noise standard to be worth the scope with $74 \mathrm{~dB}$ (A), while the red region is the scope higher than standard value.

\section{CONCLUSION AND SUGGESTION}

\subsection{Conclusion}

1. In $\mathrm{Wu}$ Kung Elementary school district environment noise distribution situation establishment of database

Because of this survey and analysis result, It may carry on in the $\mathrm{Wu}$ Kung Elementary school district the environment noise distribution situation establishment of database, favor takes when the following operation the material analysis simulation use. If can further analyze the initiation noise the factor, then makes the improvement because of the factor control to the noise present situation.

2. The improvement strategy of the community primary school environment noise drafts

This environment noise distributes the result of the situation diagraph and can know and the environment noise is very big subjected to the situation of the traffic noise influence. This research uses school district as to investigate scope to expect through acquire the current conditions that the related noise distributes situation in the data of diagraph point, then reach the purpose of the strategy of the draw-up improvement.

\subsection{Suggestions}

1. The classification of noise factor

The origin studied currently homework and measure noise as to measure object, but don't carry on analysis to the noise factor. If can then analyze to cause the factor of the noise, then improve to the noise current conditions by the control of factor.

2. The increase questionnaire, understands the inhabitant to feeling the noise present situation

At present studies the content for the noise distributed situation, by laws and regulations analysis Noise Level qualified situation, then induces a noise present situation more serious area. But obstructs to the time and the spatial limit, is unable to know the inhabitant to feeling the noise present situation. Therefore suggested increases the inhabitant to questionnaire of the noise present situation feeling, favors the noise factor classification and the noise control.

\section{REFERENCES}

[1] Dobie, R.A., MD. (1995) Prevention of Noise-Induced Hearing Loss, Archives of Otolaryngology-Head and Neck Surgery, 121: 385-441. 
[2] Evan, G.W., Hygge, S. \& Bullinger, M. (1995) Chronic Noise and Psychological Stress, Psychological Science, 6(6): 333-338.

[3] Fidell, S. \& Barber, D.S. (1991) Updating a Disageeffect Relationship for the Prevalence of Annoyance Due to General Transportation Noise, The Journal of the Acoustical Society of America, 89(1): 221-233.

[4] Wang, Han-Ming. (2004) The method study of noise mapping for urban road traffic, master thesis.

[5] Hick, C.B. (2000) Listening Effort and Fatigue in School-age Children with and without Hearing Loss, Dissertation at V\&erbilt University.

[6] Jong, R.G. (1990) Community Response to Noise: A Review of Recent Developments. Environment International, 16:515- 522.

[7] Letowski, T.K. \& Thompson, M.V. (1983) Intercepted Noise as a Tinnitus masker: an Annoyance Study, Ear and Hearing, 6:65-70.

[8] Ostergren, D.E. (2001) Real-room measurements: A Case Study in Classroom Acoustics, Dissertation at Central Michigan University.

[9] Smith, A. (1990) Noise, Performance Efficiency and Safety, International Archives of Occupational and Environmental Health, 62:1-5.

[10] Touma, J.B. (1992) Controversies in Noise-Induced Hearing Loss (NIHL), The Annals of Occupation Hygiene, 36(2):199-209.

[11] White, S.L. (2002) Incidence of Tinnitus on School-age Children, Dissertation at Central Michigan University. 